\title{
Hepatitis B Vaccination, Screening, and Linkage to Care
}

TO THE EDITOR: Abara and colleagues' (1) guideline on screening and vaccination for hepatitis B virus (HBV) infection is welcome. However, I am concerned that they did not mention the potential confounding effect of recent immunoglobulin therapy on serologic tests.

As we have described (2), passive transfer of hepatitis B antibodies is extremely common. In our cohort of patients receiving immunoglobulin therapy, at baseline $11.3 \%$ tested positive for hepatitis B surface antibody and just 1 patient had equivocal results for hepatitis B core antibody. After a median of 2 years of treatment, all patients tested positive for hepatitis B surface antibody while $46.3 \%$ and $12.5 \%$ tested positive and had equivocal results for hepatitis B core antibody, respectively. These changes took place despite most patients receiving only replacement doses of immunoglobulin and being tested at IgG trough levels (immediately preinfusion).

Immunoglobulin therapy is administered relatively rarely. However, some risk groups identified in Abara and colleagues' guidelines will be substantially more likely than the general population to be receiving immunoglobulin therapy, especially patients requiring immunosuppressive treatment (3) and those with abnormal results on liver function tests (4).

False-positive results on serologic studies from passive transfer of antibody could have 2 major consequences. Detection of hepatitis B surface antibody after recent immunoglobulin therapy may falsely reassure clinicians that vaccination is not required when the patient may actually be at risk after elimination of the infused antibody (assuming that immunoglobulin therapy is not 
continuing indefinitely). As an alternative, the detection of hepatitis B core antibody may result in patients being told that they have evidence of an infection that is usually sexually acquired, which will create anxiety and unnecessary screening of partners; in certain circumstances (for example with concomitant rituximab therapy) patients may even be started on prophylactic antivirals.

I strongly encourage Abara and colleagues to consider in their guideline recent immunoglobulin therapy when advising on the timing and interpretation of serologic studies for HBV as a screen for prior infection or immunity. I also suggest to all clinicians that the results of these studies be checked before immunoglobulin therapy is begun in order to minimize the risk for subsequent misleading results.

David M. Lowe, $\mathrm{PhD}$

University College London; London, United Kingdom

Financial Support: Dr. Lowe received support to attend a conference from Biotest and participated in an advisory board for Biotest and received travel and accommodation expenses for consultancy work from CSL Behring.

Disclosures: Disclosures can be viewed at www.acponline.org/authors/icmje/ConflictOfInterestForms.do?msNum=L18-0100. 


\section{References}

1. Abara WE, Qaseem A, Schillie S, McMahon BJ, Harris AM; High Value Care Task Force of the American College of Physicians and the Centers for Disease Control and Prevention. Hepatitis B vaccination, screening, and linkage to care: best practice advice from the American College of Physicians and the Centers for Disease Control and Prevention. Ann Intern Med. 2017;167:794-804. [PMID: 29159414] doi:10.7326/M17-1106

2. Ramsay I, Gorton RL, Patel M, Workman S, Symes A, Haque T, et al. Transmission of hepatitis B core antibody and galactomannan enzyme immunoassay positivity via immunoglobulin products: a comprehensive analysis. Clin Infect Dis. 2016;63:57-63. [PMID: 27076567] doi:10.1093/cid/ciw222

3. Hartung HP, Mouthon L, Ahmed R, Jordan S, Laupland KB, Jolles S. Clinical applications of intravenous immunoglobulins (IVIg) — beyond immunodeficiencies and neurology. Clin Exp Immunol. 2009;158 Suppl 1:23-33. [PMID: 19883421] doi:10.1111/j.1365-2249.2009.04024.X 4. Ward C, Lucas M, Piris J, Collier J, Chapel H. Abnormal liver function in common variable immunodeficiency disorders due to nodular regenerative hyperplasia. Clin Exp Immunol. 2008;153:331-7. [PMID: 18647320] doi:10.1111/j.1365-2249.2008.03711.x 